\title{
PENGARUH MODEL PEMBELAJARAN JIGSAW TERHADAP HASIL BELAJAR IPS SISWA KELAS 4 SEKOLAH DASAR
}

\author{
Marsita Dewi Widyaningrum ${ }^{\left.a^{*}\right)}$, Nyoto Harjono ${ }^{a)}$ \\ ${ }^{a)}$ Universitas Kristen Satya Wacana, Salatiga, Indonesia \\ ${ }^{*}$ e-mail korespondensi : marsitadewi19@gmail.com
}

Riwayat Artikel : diterima: 26 Maret 2019; direvisi: 16 Juni 2019; disetujui: 26 Juli 2019

\begin{abstract}
Abstrak. Tujuan dari penelitian ini adalah untuk menganalisis kembali penggunaan model pembelajaran tipe kooperatif tipe jigsaw dalam meningkatkan hasil belajar pada mata pelajaran IPS. Metode penelitian adalah meta-analisis. Penelitian dimulai dengan merumuskan masalah penelitian, kemudian menguji hasil penelitian yang relevan untuk dianalisis. Data dikumpulkan dengan menelusuri artikel, jurnal elektronik, dan esai menggunakan "hasil pembelajaran", "model jigsaw", dan "Studi Sosial Pendidikan Dasar". Hasil pencarian menunjukkan bahwa ada 12 artikel, jurnal elektronik, dan esai tetapi hanya 10 artikel yang relevan, jurnal elektronik, dan esai. Data dianalisis menggunakan analisis deskriptif kualitatif. Hasil analisis menunjukkan bahwa model pembelajaran tipe kooperatif tipe learning dapat meningkatkan hasil belajar siswa dari yang terendah 9,89\% menjadi yang tertinggi $85,56 \%$ dan rerata $46,09 \%$
\end{abstract}

Kata Kunci: Model Jigsaw, Hasil Belajar IPS, Meta-analisis.

\begin{abstract}
THE INFLUENCE OF JIGSAW LEARNING MODEL IN INCREASING THE LEARNING OUTCOME SOCIAL STUDIES (IPS) SUBJECT FOR STUDENTS IN CLASS 4 ELEMENTARY SCHOOL.

Abstract. The purpose of this research was to re-analyze the use of cooperative learning type jigsaw model in increasing the learning outcome in social studies subject. The research method was meta-analysis. The research began with formulating research problems, then trancing relevant research result to be analyzed. The data was collected by browsing article, electronic journals, and essay using "learning outcomes", "jigsaw model", and "Social Studies of Primary Education". The searching result showed that there were 12 articles, electronic journals, and essay but only 10 relevant articles, electronic journals, and essay. The data were analyzed using qualitative descriptive analysis. The analysis result showed that cooperative learning type jigsaw model could improve student's learning from the lowest $9,89 \%$ to the highest $85,56 \%$ and the mean was $46,09 \%$
\end{abstract}

Keywords: Jigsaw Model, IPS Learning Outcomes, Meta-Analysis

\section{PENDAHULUAN}

Pendidikan merupakan sarana untuk meningkatkan kualitas sumber daya manusia (SDM). Dalam UndangUndang RI No. 20 Tahun 2003 Tentang Sistem Pendidikan Nasional pada pasal 1dinyatakan bahwa "Pendidikan adalah usaha sadar dan terencana untuk mewujudkan suasana belajar dan proses pembelajaran agar peserta didik secara aktif mengembangkan potensi dirinya untuk memiliki kekuatan spiritual keagamaan, pengendalian diri, kepribadian, kecerdasan, akhlak mulia serta keterampilan yang diperlukan dirinya, masyarakat, bangsa dan negara". Karim dalam Susilo (2007) [1] mengemukakan bahwa upaya yang dilakukan untuk meningkatkan mutu pendidikan di sekolah dengan cara perbaikan proses pembelajaran. Proses pembelajaran yang baik dan tepat juga dapat mempengaruhi kualitas pembelajaran. Oleh karena itu, guru dituntut untuk memiliki kemampuan pengetahuan yang kreatif dan inovatif dalam proses pembelajaran. Dengan adanya pembelajaran yang kreatif dan inovatif, diharapkan mampu menjadikan siswa lebih aktif dalam proses kegiatan pembelajaran dan menjadikan proses kegiatan pembelajaran lebih optimal.

Model pembelajaran cooperatif learning merupakan model pembelajaran yang mampu mengaktifkan siswa dalam pembelajaran. Model cooperatif learning dilakukan dengan cara membagi siswa ke dalam beberapa kelompok kecil dan saling bekerjasama untuk mengkaji dan memecahkan masalah yang diberikan oleh guru. Menurut Slavin dalam Sanjaya [2], dinyatakan bahwa (1) penggunaan cooperatif learning dapat meningkatkan hasil belajar sekaligus dapat meningkatkan kemampuan hubungan sosial, menumbuhkan sikap menerima kekurangan diri dan orang lain, serta dapat meningkatkan harga diri, (2) pembelajaran kooperatif dapat merealisasikan kebutuhan siswa dalam berpikir, memecahkan masalah, dan mengintergrasikan pengetahuan dengan keterampilan. Metode cooperatif learning memiliki beberapa tipe dalam pelaksanaanya, salah satunya tipe jigsaw. Pembelajaran jigsaw merupakan salah satu tipe yang mendorong siswa untuk aktif dan saling membantu dalam menguasai materi pembelajaran untuk mencapai hasil belajar yang optimal

Pada penggunaan model pembelajaran jigsaw membawa banyak pengaruh, salah satunya pada hasil belajar IPS siswa pada tingkat sekolah dasar. Hasil tersebut dapat dilihat dari hasil beberapa penelitian yang telah dilakukan. Banyak penelitian-penelitian yang telah membuktikan bahwa adanya peningkatan hasil belajar setelah menggunakan model pembelajaran jigsaw.

Berdasarkan uraian tersebut, maka fokus penelitian ini yaitu apakah penggunaan model pembelajaran cooperatif learning tipe jigsaw dapat meningkatkan hasil belajar IPS. 


\section{METODE PENELITIAN}

Metode penelitian ini menggunakan jenis penelitian Meta Analisis. Meta analisis adalah penelitian yang dilakukan dengan cara menganalisis data penelitian, mengkaji, dan mereview data dari beberapa hasil penelitian yang sudah ada sebelumnya (Anugraheni [3]) Pengumpulan data dilakukan dengan menelusuri jurnal online, repository, dan google scholar atau lebih dikenal dengan google cendikia. Kata kunci yang digunakan dalam teknik pengumpulan data adalah gerakan literasi sekolah, hasil belajar, dan prestasi belajar. Dari hasil penulusuran diperoleh 12 artikel kemudian diambil 10 artikel yang relevan yang sudah diterbitkan oleh jurnal online. Teknik pengumpulan data dilakukan dengan penggunakan teknik dokumentasi. Dokumen tertulis yang digunakan berupa artikel, jurnal elektronik, dan skripsi. Artikel, jurnal dan skripsi yang diambil juga harus memenuhi kriteria penelitian yaitu pembahasan model pembelajaran jigsaw, hasil belajar IPS pada tingkat Sekolah Dasar yang relevan dengan pembelajaran IPS, dan adanya data sebelum menggunakan model pembelajaran jigsaw dan sebelum menggunakan model pembelajaran jigsaw dalam bentuk skor nilai. Teknik analisis data yang digunakan adalah deskriptif kuantitatif. Teknik analisis yang dilakukan dengan cara membandingkan antara selisih skor nilai sebelum penerapan model pembelajaran jigsaw dan sesudah penerapan model pembelajaran jigsaw. Setelah itu, dibagi dengan skor sebelum penerapan model pembelajaran jigsaw (dalam bentuk \%) untuk mengetahui presentase peningkatan hasil belajar IPS siswa tingkat Sekolah Dasar.

\section{HASIL DAN PEMBAHASAN}

Hasil penelitian yang diikutkan dalam penelitian meta analisis ini adalah:

1. Pengaruh Metode Kooperatif Jigsaw Terhadap prestasi belajar mata pelajaran IPS pada Siswa Kelas III oleh Maya Kartika Sari [4].

Tabel. 1 Hasil Analisis Model Pembelajaran Kooperatif Tipe Jigsaw Terhadap Persentase Peningkatan Hasil Belajar IPS

\begin{tabular}{|c|c|c|c|c|c|c|}
\hline \multirow[b]{2}{*}{ No } & \multirow[b]{2}{*}{ Topik Penelitian } & \multirow[b]{2}{*}{ Peneliti } & \multicolumn{4}{|c|}{ Peningkatan Hasil Belajar } \\
\hline & & & Sebelum & Sesudah & Gain & $\begin{array}{c}\text { Gain } \\
(\%)\end{array}$ \\
\hline 1. & $\begin{array}{l}\text { Metode Kooperatif Jigsow, Prestasi } \\
\text { Belajar IPS Kelas III }\end{array}$ & Maya Kartika Sari & 58,70 & 85 & 26,3 & 44,80 \\
\hline 2. & Tipe Jigscww, Hasil Belajar IPS Kelas IV & Riesa Dewi Setianingrum & 54,10 & 75,04 & 20,94 & 38,70 \\
\hline 3. & $\begin{array}{l}\text { Model Pembelajaran Kooperatif Tipe } \\
\text { Jigsaw, Hasil Belajar IPS Kelas IV }\end{array}$ & $\begin{array}{l}\text { Rina Rismawati, Rustono } \\
\text { WS, dan AkhmadNugraha }\end{array}$ & 42,25 & 78,40 & 36,15 & 85,56 \\
\hline 4. & $\begin{array}{l}\text { Model Jigsaw, Hasil Belajar IPS Kelas } \\
\text { IV }\end{array}$ & $\begin{array}{l}\text { Noviana, Mujiyono, dan } \\
\text { Jaino }\end{array}$ & 52,68 & 78,04 & 25,36 & 48,13 \\
\hline 5. & $\begin{array}{l}\text { Model Kooperatif Tipe Jigsaw, Hasil } \\
\text { Belajar IPS }\end{array}$ & Fahmi Fathori & 53,75 & 75,53 & 21,78 & 40,52 \\
\hline 6. & $\begin{array}{l}\text { Model Kooperatif Tipe Jigscw, Presta si } \\
\text { Belajar IPS Kelas IV }\end{array}$ & Teguh Eko Pamujï & 53,8 & 86,87 & 33,07 & 61,46 \\
\hline 7. & $\begin{array}{l}\text { Model Pembelajaran Kooperatif Tipe } \\
\text { Jigsaw, Hasil Belajar IPS Kelas V }\end{array}$ & Dea Ayu Pangestu & 62,66 & 78,53 & 15,865 & 25,31 \\
\hline 8. & $\begin{array}{l}\text { Model Pembelajaran Kooperatif Type } \\
\text { Jigsaw, Hasil Belajar IPS Kelas V }\end{array}$ & Amidah Sari Harahap & 40,66 & 72 & 31,34 & 77,07 \\
\hline 9. & $\begin{array}{l}\text { Model Pembelajaran Kooperatif Tipe } \\
\text { Jigsow, Hasil Belajar IPS Kelas VI }\end{array}$ & $\begin{array}{l}\text { Deboro Anmg Endekan, } \\
\text { Nyoman Dantes, dan } \\
\text { WayanLasmawan }\end{array}$ & 68,25 & 75 & 6,75 & 9,89 \\
\hline 10. & $\begin{array}{l}\text { Model Pembelajaran Jigsaw, Proses dan } \\
\text { Hasil Belajar IPS Kelas IV }\end{array}$ & $\begin{array}{l}\text { Gunawan, Siripto, dan } \\
\text { Chamdari }\end{array}$ & 66,67 & 86,33 & 19,66 & 29,48 \\
\hline Rata & ata Pengaruh Model Pembelajaran Jigsaw & & 55,352 & 79,07 & 23,72 & 46,09 \\
\hline
\end{tabular}

2. Pengaruh Penerapan Tipe Jigsaw Terhadap Hasil Belajar IPS Siswa Kelas IV SDN 2 Sabranglor oleh Riesa Dewi Setianingrum [5].

3. Pengaruh Penggunaan Model Pembelajaran Kooperatif Tipe Jigsaw Terhadap Hasil Belajar IPS Siswa Kelas IV di Sekolah Dasar oleh Rina Rismawati, Rustono WS, dan Akhmad Nugraha [6].

4. Keefektifan Model Jigsaw Terhadap Hasil Belajar IPS Siswa Kelas IV oleh Noviana, Mujiyono, dan Jaino [7].

5. Pengaruh Model Kooperatif Tipe Jigsaw Terhadap Hasil Belajar IPS Di Sekolah Dasar oleh Fahmi Fathoni [8].

6. Efektivitas Model Kooperatif Tipe Jigsaw Terhadap Presetasi Belajar IPS Pada Siswa Kelas IV SDN Bibis Bangunjiwo Kasihan Bantul Yogyakarta oleh Teguh Eko Pamuji [9].

7. Pengaruh Model Pembelajaran Kooperatif Tipe Jigsaw Terhadap Hasil Belajar IPS Siswa Kelas V SD Negeri 2 Sumberejo Kemiling Bandar Lampung oleh Dea Ayu Pangestu [10].

8. Pengaruh Model Pembelajaran Kooperatif Type Jigsaw Pada Mata Pelajaran IPS Terhadap Hasil Belajar Siswa Kelas V MIS AL Mutaqin Tanjung Putus Langkat oleh Amidah Sari Harahap [11].

9. Pengaruh Model Pembelajarn Kooperatif Tipe Jigsaw Terhadap Hasil Belajar IPS Ditinjau Dari Motivasi Berprestasi Pada Siswa Kelas VI SD Gugus IV Kuta oleh Deboro Arung Endekan, Nyoman Dantes, dan Wayan Lasmawan [12].

10. Pengaruh Model Pembelajaran Jigsaw Dalam Peningkatan Proses Dan Hasil Belajar IPS Pada Siswa Kelas V SD oleh Gunawan, Siripto, dan Chamdani [13]

Data yang digunakan untuk penelitian in masih luas dan banyak sehingga data diolah dengan cara dirangkum dan diambil intisarinya saja. Setelah itu data tersebut dianalisis dengan metode pembanding kuantitatif. Hasil analisis pengaruh metode pembelajaran Jigsaw terhadap hasil belajar mata pelajaran IPS dapat dilihat pada tabel 1 .

Berdasarkan hasil analisis pada tabel 1 tersebut dapat dilihat bahwa model pembelajaran cooperatif learning tipe jigsaw dapat meningkatkan hasil belajar IPS. Peningkatan hasil belajar dari mulai yang terendah $9,89 \%$. sampai yang tertinggi $85,56 \%$ dengan rata-rata sebesar 46,09\%. Hasil belajar rata-rata sebelum menggunakan model pembelajaran cooperatif learning tipe jigsaw dan sesudah menggunakan model pembelajaran cooperatif learning tipe jigsaw mengalami peningkatan yang signifikan yaitu sebesar $46,09 \%$. 
Tabel.2 Berikut Tabel Paired Samples Statistics

\begin{tabular}{lcc|c|r|r}
\multicolumn{7}{c}{ Paired Samples Statistics } & \\
& & Mean & N & Std. Deviation & Std. Error Mean \\
\hline \multirow{2}{*}{ Pair 1 } & Sebelum & 55,3520 & 10 & 9,19100 & 2,90645 \\
\cline { 2 - 6 } & & & & & 1,65275 \\
\hline
\end{tabular}

Berdasarkan Tabel 2 menunjukkan bahwa penggunakan model pembelajaraan cooperatif learning tipe jigsaw dapat meningkatkan hasil belajar IPS dengan nilai rata-rata 55,352 menjadi 79,07. Tabel 3 diatas menunjukkan adanya relasi antara nilai rata-rata hasil belajar IPS siswa sebelum dan sesudah menggunakan model pembelajaran Kooperatif Tipe Jigsaw sebesar 0,369.

Tabel.3 Berikut Tabel Paired Samples Correlations

\begin{tabular}{|c|c|c|c|c|}
\hline \multicolumn{5}{|c|}{ Paired Samples Correlations } \\
\hline & & $\mathrm{N}$ & Correlation & Sig. \\
\hline Pair 1 & $\begin{array}{l}\text { Sebelum \& } \\
\text { Sesudah }\end{array}$ & 10 &, 369 & ,294 \\
\hline
\end{tabular}

Hasil uji hipotesis, Ho = tidak terdapat perbedaan yang signifikan terhadap hasil belajar IPS siswa sebelum menggunakan model pembelajaran cooperatif learning tipe jigsaw dan sesudah menggunakan model pembelajaran kooperatif Tipe Jigsaw dan $\mathrm{H}_{1}=$ terdapat perbedaan yang signifikan hasil belajar IPS siswa sebelum menggunakan model pembelajaran cooperatif learning tipe jigsaw dan sesudah menggunakan model pembelajaran cooperatif learning tipe jigsaw. Dari tabel 3 tampak bahwa nilai Sig. (2-tailed) $(0,000)<\alpha(0,05)$ dan $\mathrm{t}_{\text {hitung }}=-8,586<\mathrm{t}_{\text {tabel }}=$ 2,30600 sehingga Ho ditolak. Jadi dapat disimpulkan bahwa terdapat perbedaan yang signifikan hasil belajar IPS siswa sebelum menggunakan model pembelajaran cooperatif learning tipe jigsaw dan sesudah menggunakan model pembelajaran cooperatif learning tipe jigsaw.

Tabel.4 Berikut Tabel Paired Samples Test

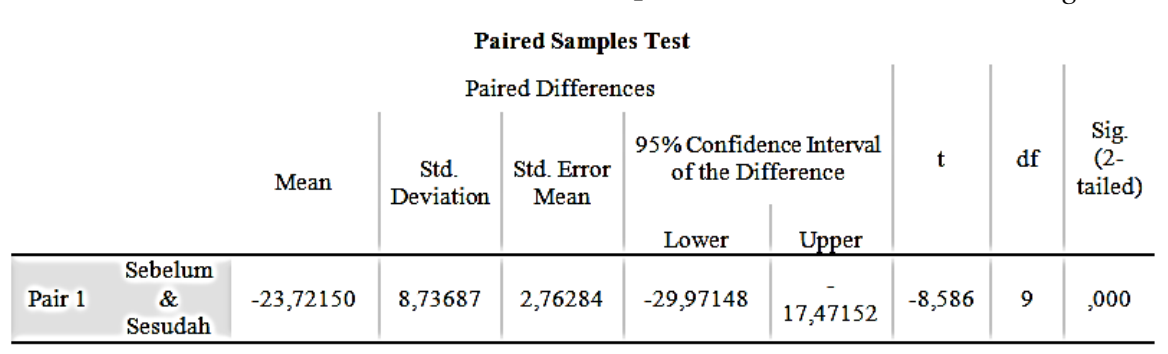
2018. tersebut dipengaruhi oleh berbagai faktor, baik faktor internal siswa maupun faktor eksternal siswa. Faktor internal atau faktor yang berasal dari dalam diri individu, misalnya tingkat kemampuan kognitif (pengetahuan), cara berfikir, kemampuan, minat, bakat, kesehatan, dan sebagainya. Faktor eksternal siswa atau faktor yang berasal dari luar diri individu, misalnya keluarga, waktu, lingkungan sekolah, kondisi sekolah, letak sekolah, dan subjek penelitian.

\section{SIMPULAN}

Berdasarkan hasil analisis model pembelajaran cooperatif learning tipe jigsaw, dapat disimpulkan bahwa model pembelajaran jigsaw mampu meningkatkan hasil belajar IPS SD siswa mulai dari yang terendah 9,89\% sampai yang tertinggi $85,56 \%$ dengan rata-rata sebesar $46,09 \%$. Saran bagi penelitian selanjutnya supaya dapat menggunakan artikel atau sumber lainnya yang lebih banyak dan relevan. Diharapkan dalam penelitian selanjutnya peneliti mampu agar lebih ketat dalam menyeleksi dan memilih hasil penelitian yang akan digunakan dalam penelitian meta-analisis, dan penggunaan metode statistik perlu diperhatikan agar hasil dari meta-analisis yang diperoleh lebih akurat.

\section{REFERENSI}

[1] Susilo, Joko M. 2008. Kurikulum Tingkat Satuan Pendidikan. Yogyakarta: Pustaka Pelajar.

[2] Sanjaya, Wina. "Strategi Pembelajaran". Jakarta: Prenada Media Grup. 2016.

[3] Anugraheni, I. "Meta Analisis Model Pembelajaran Problem Based Learning dalam Meningkatkan Keterampilan Berpikir Kritis di Sekolah Dasar [A Meta-analysis of Problem-Based Learning Models in Increasing Critical Thinking Skills in Elementary Schools]". Polyglot: Jurnallmiah, vol.20, pp. 9-18.

[4] Kartika, Maya Sari. "Pengaruh Metode Kooperatif Jigsaw Terhadap Prestasi Belajar Mata Pelajaran Ips Pada Siswa Kelas III'. Jurnal Premiere Educantum, vol. 4, pp.133146. 2014

[5] Dewi, Riesa Setianingrum. (2016). "Pengaruh Penerapan Tipe Jigsaw Terhadap Hasil Belajar Ips Siswa Kelas Iv Sdn 2 Sabranglor”. Jurnal Pendidikan Sekolah Dasar. Edisi $17 . \quad$ [Online]. journal.student.uny.ac.id/ojs/index.php

Berdasarkan hasil analisis penelitian dapat kita lihat bahwa penggunaan model pembelajaran cooperatif learning tipe jigsaw dari masing-masing penelitian dapat meningkatkan hasil belajar siswa. Peningkatan hasil belajar yang ada pada masing-masing penelitian memiliki tingkat presentase yang berbeda-beda. Presentase yang dimiliki juga beragam mulai dari yang rendah, cukup dan tinggi. Hal /pgsd/article/download/2120/1816.

[6] Rismawati, Rina, Rustono WS, dan Akhmad Nugraha. "Pengaruh Penggunaan ModelPembelajaran Kooperatif Tipe Jigsaw terhadap Hasil Belajar IPS Siswa Kelas IV di Sekolah Dasar". Jurnal Ilmiah Pendidikan Guru Sekolah Dasar, vol 2, pp. 218-226. 2017. 
[7] Noviana, Mujiyono, dan Jaino. "Keefektifan Model Jigsaw Terhadap Hasil Belajar IPS Siswa Kelas IV'. Jurnal Kreatif, vol. 4, pp. 120-129. 2017.

[8] Fathoni, Fahmi. (2016). "Pengaruh Model Kooperatif Tipe Jigsaw Terhadap Hasil Belajar Ips Di Sekolah Dasar". Artikel Penelitian. Program Studi Pendidikan Guru Sekolah Dasar Fakultas Keguruan Dan Ilmu Pendidikan Universitas Tanjungpura Pontianak. [Online]. jurnal.untan.ac.id/index.php/jpdpb/article /download/17351/14797.

[9] Eko, Teguh Pamuji. (2015). "Efektivitas Model Kooperatif Tipe Jigsaw Terhadap Prestasi Belajar Ips Pada Siswa Kelas Iv Sdn Bibis Bangunjiwo Kasihan Bantul Yogyakarta". Artikel. [Online]. jurnal.untirta.ac.id/index.php/jpsd/article/view/3870.

[10] Ayu, Dea Pangesti. (2017). "Pengaruh Model Pembelajaran Kooperatif Tipe Jigsaw Terhadap Hasil Belajar IPS Siswa Kelas V SD Negeri 2 Sumberejo Kemiling Bandar Lampung". Skripsi di publikasikan. Program Studi Pendidikan Guru Sekolah Dasar Jurusan Ilmu Pendidikan. [Online]. http://jurnal.fkip.unila.ac.id /index.php/pgsd/article/view/15285.

[11] Sari, Amidah Harahap. (2018). "Pengaruh Model Pembelajaran Kooperatif Type Jigsaw Pada Mata Pelajaran Ips Terhadap Hasil Belajar Siswa Kelas V Mis Al Muttaqin Tanjung Putus Langkat". Skripsi. Pendidikan Guru Madrasah Ibtidaiyah (Pgmi) Fakultas Ilmu Tarbiyah Dan Keguruan Universitas Islam Negeri Sumatera Utara Medan. [Online]. http://repository.uinsu.ac.id/3834/.

[12] Arung, Debora Endekan., dkk. "Pengaruh Model Pembelajaran Kooperatif Tipe Jigsaw Terhadap Hasil Belajar Ips Ditinjau Dari Motivasi Berprestasi Pada Siswa Kelas VI Sd Gugus IV Kuta". Jurnal Pendidikan Dasar Indonesia, vol. 4. 2014.

[13] Gunawan., dkk. "Penerapan Model Pembelajaran Jigsaw Dalam Peningkatan Proses Dan Hasil Belajar Ips Pada Siswa Kelas V SD”. Jurnal FKIP UNS, vol.3. 2015. 